\title{
Letter to the editor: A norovirus intervariant GII.4 recombinant in Victoria, Australia, June 2016: the next epidemic variant? Reflections and a note of caution
}

J Fonager ${ }^{1}$, LD Rasmussen ${ }^{1}$, TK Fischer ${ }^{1}$

1. Virology Surveillance and Research Section, Department of Microbiological Diagnostics and Virology, Statens Serum Institut, Copenhagen, Denmark

Correspondence: Jannik Fonager (FON@ssi.dk)

Citation style for this article:
Fonager J, Rasmussen LD, Fischer TK. Letter to the editor: A norovirus intervariant GII.4 recombinant in Victoria, Australia, June 2016: the next epidemic variant? Reflections and a note of caution. Euro Surveill. 2016;21(41):pii=30372. DOI: http://dx.doi.org/10.2807/1560-7917. ES.2016.21.41.30372

To the editor: We wish to offer some cautionary remarks concerning the report by Bruggink et al. [1]. From an initial reading of the article, one could get the impression that the GII.P4_New_Orleans_2009_GII.4_ Sydney_2012 recombinant form has only been possibly detected once before this study [2] and has - due to indicated novelty - a yet unknown pandemic potential. However, the GII.P4_New_Orleans_2009_GII.4_ Sydney_2012 recombinant form has been reported earlier, both by us [3] in 2013 as well as by others [4,5]. The ORF1-ORF2 intergenic sequence (KXo64756.1) submitted by the authors is almost identical (99.3\%; 748 of $753 \mathrm{bp}$ ) to one of the sequences we submitted to the National Center for Biotechnology Information/ GenBank in 2013 (KF199164.1), yet the authors only show separate phylogenies of the ORF1 fragment and capsid genes in their manuscript, masking the homology with previously published intergenic sequences.

We further consider it misleading that the authors do not mention that this recombinant form has been known to be in circulation since late 2012 and also that no phylogeny was presented based on alignments between their own ORF1/ORF2 spanning sequence (KXo64756.1) and similar sequences from earlier studies. This gives the impression that no ORF1/ORF2 spanning sequences from the GII.P4_New_Orleans_2009_GII.4_ Sydney_2012 are available in public databases, which indeed they are.

Also, since this recombinant contains the Gll.4_ Sydney_2012 capsid region (which is the most likely target for any acquired herd immunity), we find it unclear how recombination with a (internal) pol gene could be beneficial for the virus to escape the increasingly acquired herd immunity against the GII.4_ Sydney_2012 capsid region.
Finally, we find that when the authors propose that the Sydney 2012 has a potential to become a new pandemic norovirus strain, it is highly important to also mention that it has been identified earlier and not give the impression that this is the first report about this recombinant strain.

Conflict of interest

None declared.

Authors' contributions

Jannik Fonager conceived the idea of a letter, and wrote the first draft. Lasse Dam Rasmussen and Thea Kølsen Fischer critically revised the manuscript. Lasse Dam Rasmussen compared sequences submitted to GenBank.

\section{References}

1. Bruggink L, Catton M, Marshall J. A norovirus intervariant Gll.4 recombinant in Victoria, Australia, June 2016: the next epidemic variant?Euro Surveill. 2016;21(39): pii=30353. http:// dx.doi.org/10.2807/1560-7917.ES.2016.21.39.30353

2. Centers for Disease Control and Prevention (CDC). CaliciNet Data. Atlanta, GA: CDC. [Accessed 28 Sep 2016]. Available from: http://www.cdc.gov/norovirus/reporting/calicinet/data. html

3. Fonager J, Barzinci S, Fischer TK. Emergence of a new recombinant Sydney 2012 norovirus variant in Denmark, 26 December 2012 to 22 March 2013.Euro Surveill. 2013;18(25):20506. DOI: 10.2807/1560-7917. ES2013.18.25.20506 PMID: 23806295

4. Wong TH, Dearlove BL, Hedge J, Giess AP, Piazza P, Trebes $A$, et al. Whole genome sequencing and de novo assembly identifies Sydney-like variant noroviruses and recombinants during the winter 2012/2013 outbreak in England. Virol J. 2013;10(1):335. DOI: $10.1186 / 1743-422$ X-10-335 PMID: 24220146

5. Martella V, Medici MC, De Grazia S, Tummolo F, Calderaro A, Bonura F, et al. Evidence for recombination between pandemic GII.4 norovirus strains New Orleans 2009 and Sydney 2012. J Clin Microbiol. 2013;51(11):3855-7. DOI: 10.1128/JCM.01847-13 PMID: 23966499 


\section{License and copyright}

This is an open-access article distributed under the terms of the Creative Commons Attribution (CC BY 4.0) Licence. You may share and adapt thez material, but must give appropriate credit to the source, provide a link to the licence, and indicate if changes were made.

This article is copyright of the authors, 2016. 